\title{
CRIANÇA ENQUANTO SUJEITO DE DIREITO NO DEPOIMENTO ESPECIAL E A EXPERIÊNCIA EM MATO GROSSO DO SUL
}

\author{
CHILD AS A SUBJECT OF RIGHTS IN SPECIAL TESTIMONY AND EXPERIENCE \\ IN MATO GROSSO DO SUL
}

\author{
Ana Maria Assis de Oliveira \\ Universidade Federal de Mato Grosso do Sul \\ Mestranda em Direitos Humanos (UFMS) \\ Professora na EJUD-MS \\ Campo Grande-MS, Brasil \\ anamaria.jus@gmail.com \\ Rejane Alves de Arruda \\ Universidade Federal de Mato Grosso do Sul \\ Doutora em Direito (PUC-SP) \\ Professora na Faculdade de Direito da UFMS \\ Campo Grande-MS, Brasil \\ rejane.arruda@hotmail.com
}

\begin{abstract}
Resumo: A pesquisa aborda a aplicação do depoimento especial no Brasil, respondendo ao seguinte problema: $\mathrm{O}$ depoimento especial incorpora o reconhecimento da criança enquanto sujeito de direito? Preliminarmente, acredita-se que a técnica apresenta mais harmonia com os princípios de proteção integral e prioridade absoluta, em comparação com os métodos tradicionais de oitiva. O objetivo é demonstrar como a técnica está sendo aplicada no Brasil, considerando o paradigma da criança enquanto sujeito de direito e, ainda, as características do depoimento pessoal e os dados do Poder Judiciário de Mato Grosso do Sul. Os métodos utilizados para a pesquisa são bibliográfico e documental. A conclusão é de que, embora esteja em período de aperfeiçoamento, o depoimento especial representa um avanço quanto ao reconhecimento da criança enquanto sujeito, enquanto alguém a ser ouvido.
\end{abstract}

Palavras-chave: direito da criança; depoimento especial; proteção integral.

Abstract: The research addresses the application of special testimony in Brazil, responding to the following problem: Does the special testimony incorporate the recognition of the child as a subject of law? Preliminarily, it is believed that the technique presents more harmony with the principles of integral protection and absolute priority, in comparison with the traditional methods of hearing. The objective is to demonstrate how the technique is being applied in Brazil, considering the paradigm of the child as a subject of law and, also, the characteristics of the personal testimony and the data of the Judicial Power of Mato Grosso do Sul. The methods used for the research are bibliographic and documentary. The conclusion is that, although it is in a period of improvement, the special testimony represents an advance in terms of recognizing the child as a subject, as someone to be heard.

Keywords: child law; special testimony; comprehensive protection. 
OLIVEIRA, Ana Maria Assis de; ARRUDA, Rejane Alves de. Criança enquanto sujeito de direito no depoimento especial e a experiência em Mato Grosso do Sul. Revista Thesis Juris - RTJ, São Paulo, v. 10, n. 2, p. 402-426, jul./dez. 2021.

http://doi.org/10.5585/rtj.v10i2.19321.

\section{Introdução}

Este artigo aborda a aplicação do depoimento especial no Brasil, técnica que foi instituída pela Lei 13.341 de 2017 para oitiva de crianças e adolescentes vítimas de violência sexual. O assunto é explorado a partir do paradigma da criança enquanto sujeito de direito, que é a base doutrinária que sustenta a necessidade da oitiva da criança. Posteriormente, são apresentadas as características do depoimento especial no Brasil e, em seguida, dados inéditos do Poder Judiciário de Mato Grosso do Sul quanto a aplicação da técnica.

Em três décadas de existência, o Estatuto da Criança e do Adolescente positivou garantias que visam o reconhecimento da criança e do adolescente enquanto sujeito de direito. Alimentação, segurança, lazer, educação, dignidade. Além dos direitos fundamentais elencados na Constituição Federal de 1988, crianças e adolescentes gozam de proteção integral e prioridade absoluta conforme a normativa especial brasileira, normativa esta que já estava prevista na Carta Magna.

Instituído pela Lei 8.069 de 1990, o Estatuto da Criança e do Adolescente promove direitos também garantidos em documentos internacionais relacionados à infância, o principal deles é a Convenção Sobre os Direitos da Criança de 1989, da Organização das Nações Unidas, da qual o Brasil é signatário.

Embora o discurso e a legislação caminhem no sentido da promoção de direitos, a realidade estatística do país é preocupante. Conforme dados do Fundo das Nações Unidas para a Infância (Unicef), 31 crianças ou adolescentes morrem por dia vítimas de violência no Brasil. De acordo com o Conselho Nacional de Justiça (CNJ), o número de processos novos de estupros de vulnerável quase dobrou de 2014 a 2019, passando de 39 mil para 76 mil e o número de processos de prostituição ou exploração sexual de vulnerável também aumentou (CNJ, 2020).

No desafio de mudar essa realidade, desde a promulgação do Estatuto da Criança e do Adolescente a prática e olhar sobre essas pessoas são objeto de discussão no âmbito legislativo e judiciário. Atribuir à criança e ao adolescente a condição de sujeito de direito, enquanto vulnerável a violações precoces das condições mínimas para uma existência digna, implica o 
reconhecimento de garantias processuais no âmbito cível e penal, o reconhecimento de direitos fundamentais atribuídos a um adulto, mas sem anular o reconhecimento da adequação prática e de discurso às necessidades do ser humano em desenvolvimento. Uma criança sendo vista como criança, e não como adulto em miniatura.

A violência intrafamiliar contra a criança, no âmbito civil, gera processos de perda do poder familiar ou medidas de proteção, enquanto que no âmbito penal, gera a persecução penal, transformando o agressor em réu. A voz da vítima, criança ou adolescente, enquanto sujeito de direito, deve ser ouvida. A pergunta que ainda se faz é: como?

A oitiva da criança em juízo é procedimento ainda mais delicado, complexo. Isso, pois, a maioria dos casos de violência ocorre no ambiente intrafamiliar que é permeado de segredos, conflitos, pode ser tóxico a ponto de mascarar por anos algum tipo de violência. Não é incomum, por exemplo, que o padrasto de uma criança seja o agressor, e que a mãe da criança não acredite ou seja ameaçada para manter a situação.

Nem toda violência deixa vestígios materiais. A palavra da criança e adolescente nesses casos é ainda mais importante. Não apenas no âmbito penal, no sentido de penalizar o agressor com o peso de prova testemunhal, mas o risco de não a ouvir é também de que ela continue no ambiente familiar de quem pratica a violência.

As justiças cível e penal funcionam em sistema a cada dia mais integrado, processos eletrônicos nos quais as peças podem ser transferidas a requerimento das partes, portanto o depoimento de uma criança é prova para aplicação de uma pena, de fato existe esse peso, mas também é prova para aplicação de uma medida protetiva que pode ser necessária para resguardar a sua segurança. Quanto à colocação de criança em família substituta especificamente, o Estatuto da Criança e do Adolescente traz uma previsão de que ela precisa ser ouvida e não necessariamente em ambiente judicial.

Quando se fala em ouvir a criança em juízo, há de se considerar que o ambiente de uma audiência, perante um juiz, promotor, defensor ou advogado, é carregado de estigma, formalidades, um ritual que causa estranheza, incômodo, vergonha, até mesmo a um adulto, uma testemunha de um roubo ou furto que seja. Para uma criança vítima de abuso sexual, envolve muito mais sentimentos, emoções, medo. Uma criança, que teve direitos violados por alguém que teria que protegê-la, passando por uma audiência, na qual precisa relembrar do momento de dor, implica em revitimização.

Como equilibrar, portanto, a necessidade de a criança ser ouvida e, ainda, seu direito ao bem-estar, considerada sua condição de desenvolvimento, a proteção integral, a prioridade 
absoluta? Por isso a importância do estudo do depoimento especial sob a luz do reconhecimento da criança enquanto sujeito de direito.

O tema central deste trabalho, que é o depoimento especial no Brasil e sua aplicação no estado de Mato Grosso do Sul, é vinculado ao problema da constitucionalidade e da efetividade da Lei 13.431 de 2017, na busca por responder perguntas como: "O depoimento especial incorpora o reconhecimento da criança enquanto sujeito de direito?”. A justificativa desta pesquisa é a relevância de se discutir como o Poder Judiciário atua no combate à exploração e abuso sexual infantil, que ainda é uma questão social preocupante em nosso país.

Após a abordagem bibliográfica do paradigma do reconhecimento da criança enquanto sujeito de direito, bem como do depoimento especial no Brasil, o artigo apresenta dados documentais do Tribunal de Justiça de Mato Grosso do Sul, o qual adota a prática do depoimento especial desde 2014 e cedeu informações para esta pesquisa referentes a todo período de aplicação da técnica, com atualização até o dia 9 de março de 2020.

A metodologia utilizada envolve, portanto, pesquisa bibliográfica, ao apresentar o paradigma da criança enquanto sujeito de direito e o depoimento especial; e documental ao apresentar dados do Tribunal de Justiça de Mato Grosso do Sul. Para que este trabalho fosse possível, foi feita uma solicitação formal à Coordenadoria da Infância e Juventude do Tribunal de Justiça de Mato Grosso do Sul, a solicitação foi atendida, os dados foram fornecidos em gráficos que estão disponíveis ao final deste trabalho.

Preliminarmente, acredita-se que a técnica do depoimento especial apresenta mais harmonia com os princípios de proteção integral e prioridade absoluta, em comparação com os métodos tradicionais de oitiva.

A abordagem dos direitos fundamentais em uma pesquisa jurídica, conforme Guerra Filho (2005), pode explorar três visões do tema: analítico, empírico e normativo. Sobre a visão analítica, abordamos de modo preciso o conceito de direitos fundamentais, o distinguindo de outros e demonstrando situações jurídicas, considerando o contexto histórico. Já quanto à visão empírica, pode ser no sentido normativo real ou de argumentação jurídica. E na visão crítica normativa, pode ser vista como doutrina, problemas de complementação e fundamentação. A proposta deste artigo é dar relevo às visões empírica e crítica normativa, em uma abordagem da interpretação dos princípios constitucionais conforme a própria sistemática da constituição. 


\section{Depoimento especial: a criança enquanto sujeito de direito}

Direito de ser ouvida e direito de ser protegida. Como equilibrar, portanto, a necessidade de a criança ser ouvida e, ainda, seu direito ao bem-estar, considerada sua condição de desenvolvimento, a proteção integral, a prioridade absoluta? Como não revitimizar a criança em situação de violência?

Nesse sentido, diversos países se esforçam em práticas e experiências para manter a oitiva das crianças em processos judiciais respeitando ao máximo a condição peculiar de desenvolvimento.

No direito espanhol por exemplo, a criança pode ser ouvida se tiver maturidade suficiente. Não é necessário que tenha 12 anos, mas que tenha consciência e maturidade para depor. Já no sistema português, o art. 84 da Lei de Proteção à Criança e ao Jovem em Perigo (Lei n. 147/99, de 1 de setembro) prevê que a criança pode ser ouvida de forma individual ou acompanhada de alguém que ela mesma escolhe Embora o sistema português reconheça o impacto negativo do depoimento, mantém a possibilidade da oitiva da criança, mas evitando a repetição do depoimento (ALKIMIN, 2016, p. 20).

No Brasil, é praticada a técnica do depoimento especial. Primeiro, por iniciativa do Poder Judiciário do Rio Grande do Sul a partir de 2003, depois, por meio da Recomendação 33 de 2010 do Conselho Nacional de Justiça e, enfim, foi instituído na Lei 13.431 de 2017. Conforme a lei, um técnico qualificado para ouvir a criança é quem reformula perguntas do juiz, promotor e defensor, em uma linguagem que respeite a condição de desenvolvimento da criança, em uma sala separada e preparada para receber a criança, que não tem contato com os envolvidos no processo, parte ou juristas.

José Antônio Daltoé Cezar foi quem teve a iniciativa de implantar o depoimento especial pela primeira vez no Brasil, na comarca de Porto Alegre, quando era juiz da $2^{\text {a }}$ Vara da Infância e Juventude daquela localidade, e ele já defendia a edição de uma lei que regulamentasse a prática, o que no seu entendimento atenderia o mandamento constitucional.

[...] é um direito da criança ser ouvida nos processos judiciais e administrativos que lhe respeitem, e não mera prerrogativa da autoridade judiciária [...], se propõe atualizar o ordenamento jurídico nacional, que em momento algum, até esta data, cuidou de contextualizar as determinações contidas no artigo 227 da Constituição Federal (CEZAR, 2010, p. 71).

Portanto, como ferramenta para proteção integral, no sentido de ouvir a criança judicialmente com uma linguagem mais adequada é que foi instituído por lei o depoimento especial. A função do depoimento especial é compor a instrução probatória não apenas no 
sentido de promover o combate à impunidade, na busca da utópica verdade real, mas no sentido de ouvir a criança para que sejam identificadas as suas necessidades. A criança tem o direito de falar, e também de ficar em silêncio. O técnico, qualificado conforme os princípios de proteção à criança com a linguagem não violenta, transmite as perguntas que por um juiz ou promotor, evitando assim que eles façam perguntas de forma direta e possam constranger a criança, mesmo que não haja intenção.

A prática do depoimento especial divide opiniões. Alexandre Morais da Rosa, no prefácio do livro de Maria Regina Fay de Azambuja, afirma:

O Depoimento Especial preocupa-se com uma única questão: melhorar a qualidade da prova para a condenação, fingindo respeito à criança vítima. Há técnicas qualificadas para obtenção de provas, como perícia, quesitos, etc., capazes de, ao mesmo tempo, servirem como fonte de prova e garantia de dignidade às crianças vítimas. O espetáculo do vem apresentado pelo Depoimento Especial atente a interesses estranhos ao da criança, por isso, minha recusa visceral ao procedimento. (AZEMBUJA, 2017, p. 12-13)

Para Azambuja, o depoimento especial é a inquirição com nova roupagem. A autora destaca em seu livro publicado em 2017, mesmo ano da promulgação da lei do depoimento especial, questionamentos sobre a revitimização da criança e do adolescente e, também, a responsabilização das vítimas por todo conteúdo probatório de um processo que, geralmente, envolve consequências a sua família. A autora destaca a diferença entre inquirir e ouvir.

\footnotetext{
Qual a diferença entre inquirir e ouvir a criança? Inquirir significa perguntar, indagar, fazer perguntas direcionadas, investigar, pesquisar. Ouvir, por sua vez, significa escutar o que ela tem a dizer, dar ouvidos, dar atenção às palavras da criança, o que pode vir expresso através do brinquedo, como valioso instrumento utilizado por profissionais da saúde mental na avaliação da criança. (AZAMBUJA, 2017, p. 180181)
}

Para esses autores, que criticam o depoimento especial, há a transferência de um peso da prova sobre os ombros da criança. Para eles, ouvir a criança é escutá-la sem indução ou manipulação, sem induzi-las com perguntas. Nesse sentido, o Conselho Federal de Psicologia publicou nota técnica recomendando que psicólogos não participem do procedimento do depoimento especial, apontando fragilidades na legislação (Conselho Federal de Psicologia, 2018).

Além da quebra da proteção integral da criança, assim interpretada pelos críticos do depoimento especial, juristas argumentam também sobre a violação de garantias processuais na defesa dos acusados de violência contra a criança. A crítica é de que o direito da criança em ser ouvida é deturpado e se transforma em mero meio de prova contra o ofensor, em busca da 


\title{
OLIVEIRA, Ana Maria Assis de; ARRUDA, Rejane Alves de. Criança enquanto sujeito de direito no depoimento especial e a experiência em Mato Grosso do Sul
}

verdade real que é inalcançável e não deve flexibilizar direitos ou abrir campo para falsas memórias em um depoimento. Conforme argumenta Zavattaro e Avila:

\begin{abstract}
O direito da criança em ser ouvida, conceder sua opinião e falar sobre o trauma que sofreu quando vítima de um crime abrange a necessidade de o ofendido em reconstruir sua autoestima e expressar sua emoção, garantindo que possa superar o ocorrido e reduzir os danos que lhe foram causados. Entretanto, esse direito, no caso da Lei $\mathrm{n}^{\mathbf{}}$. 13.431/2016, é deturpado como um meio de produção de prova criminal contra o ofensor.

Dentre os direitos de qualquer vítima de abuso está o de ver o seu ofensor punido. No entanto, há outros meios de prova para tanto, sem que, no caso da criança, essa tenha que ser submetida ao processo de revitimização (in)evitável dentro do sistema judiciário, independentemente da maneira de coleta das informações que tem a prestar. (ZAVATTARO \& AVILA, 2017, p. 35)
\end{abstract}

No entanto, em um artigo sobre o entendimento da Corte Interamericana de Direitos Humanos sobre a oitiva judicial de crianças e adolescentes, Zavattaro, Avila e Ribeiro, fizeram uma ponderação sobre suas próprias críticas anteriores. A respeito da Lei 13.342 de 2017, disseram que "apesar da necessidade de aperfeiçoamento do procedimento, é início da tentativa do legislador brasileiro de proteger o direito da criança em ser ouvida e respeitada, há muito já reconhecido internacionalmente" (2017, p. 900). Os autores concluíram ainda que:

\footnotetext{
De todo o exposto, interpretando o direito da criança em ser ouvidas em todos os processos penais em que figure como vítima, a dispensa arbitrária de sua opinião enseja o acionamento da Comissão Interamericana de Direitos Humanos, com a consequente anulação do processo.

Como dito, a emissão da opinião não é obrigatória para a criança, devendo ser respeitada, inclusive, o seu direito em querer ou não falar sobre os fatos dos quais foi vítima. Entretanto, em manifestando sua vontade de falar, em especial como vítima, seu direito impõe ao Poder Judiciário o dever de sua oitiva. (p. 911)
}

Aury Lopes Júnior e Alexandre Morais da Rosa também já escreveram críticas à Lei 13.341. Mencionam a abertura para criação de falsas memórias, que podem poluir a prova constituída por meio do depoimento especial (LOPES JÚNIOR \& DA ROSA, 2015). Por outro lado, há também os que defendem a prática do depoimento especial e entendem que a técnica da escuta atende aos interesses da criança e do adolescente, incluindo a proteção integral e a prioridade absoluta, ao minimizar as características do diálogo que poderia revitimizar esses indivíduos em formação:

A prática do depoimento sem dano, que envolve o cuidado especial e o melhor interesse da criança é o caminho para permitir o envolvimento da criança no processo judicial, cujo depoimento da criança é de suma importância para penalização do culpado, sem perder de vista a proteção especial e o melhor interesse, princípios basilares do sistema de proteção, que prevalecem, inclusive, sobre o jus puniendi do Estado. (ALKIMIN, 2016, p. 23) 
Portanto, as questões que envolvem as críticas ao depoimento especial ou os elogios a técnica permeiam a interpretação do princípio da proteção integral, as garantias do acusado de abuso sexual, a revitimização ou não da criança. Para alguns juristas, o princípio da proteção integral legitima a prática do depoimento especial conforme as regras da Lei 13.341, com a participação do juiz, promotor e defensores em outra sala, separada da sala em que permanece a criança sendo ouvida. Para outros, o princípio da proteção integral afasta a aplicabilidade da técnica, não suportando que a criança seja responsabilizada por uma prova e, ainda, como entendem alguns autores, estratégia por mera busca da verdade real (POTTER \& HOFFMEISTER, 2016, p.185).

Todos os argumentos fundamentados nos princípios gerais do direito e específicos da criança, a fim de analisar a regra, devem ser considerados. Afinal, como afirma Costa e Ribas "problematizar a jurisdição é reconhecer como ela se apresenta no momento para reavaliar quais padrões que merecem ser mantidos e ter condições de revelar aqueles que devem ser revistos" (2017, p. 195). Para o aperfeiçoamento das ferramentas utilizadas para combater a violência e a impunidade, a reflexão é fundamental.

Partindo do entendimento que a criança tem os mesmos direitos fundamentais que o adulto, e esses direitos devem apenas serem adaptados à condição de desenvolvimento em que elas se encontram, e não serem anulados, é necessário considerar como a vítima adulta é ouvida. De acordo com o artigo 201 do Código de Processo Penal, "sempre que possível, o ofendido será qualificado e perguntado sobre as circunstâncias da infração, quem seja ou presuma ser o seu autor, as provas que possa indicar, tomando-se por termo as suas declarações”.

Ao diferenciar a aplicação de uma regra do Direito a um ser humano por ele ser criança ou adolescente, é preciso ter justificativa que não seja apenas a proteção integral. Isso, pois, deliberadas vezes na doutrina da situação irregular o entendimento de que as autoridades sabiam o que era melhor para crianças chegou a justificar violações de diretos humanos.

Nos Estados Unidos, por meio da doutrina chamada parens patriae, com a alegação de que seria para o bem da criança, o Estado promovia o afastamento familiar sem o devido processo legal, que é garantia em processos criminais, com a mera suposição de que isso evitaria o envolvimento daquela criança com a criminalidade (TRÉPANIER, 1999, p. 306).

Portanto, quando há um direito, como o direito da vítima em ser ouvida, é necessário que o direito seja estendido à criança e ao adolescente, respeitando os demais princípios que norteiam a proteção da infância. É por essa razão que o depoimento especial não representa uma obrigação. A criança tem o direito a falar, e também a permanecer calada, assim como o adulto, a fim de que se sinta protegida. Nesse sentido, alerta Katy Braun do Prado, que é juíza 
da Vara da Infância, Adolescência e Idoso na comarca de Campo Grande, em Mato Grosso do Sul:

\begin{abstract}
O interesse do Estado é secundário ao interesse da vítima, mas é preciso refletir se o falar da criança sempre será prejudicial para suas emoções, pois a criança pode encontrar no juízo o sentimento de proteção de que necessita para romper com a síndrome do segredo e encontrar nessa experiência ajuda para compreender o ocorrido. (POTTER, 2019, p. 83)
\end{abstract}

Conforme a Lei 13.341 de 2017, “escuta especializada é o procedimento de entrevista sobre situação de violência com criança ou adolescente perante órgão da rede de proteção, limitado o relato estritamente ao necessário para o cumprimento de sua finalidade", enquanto que "depoimento especial é o procedimento de oitiva de criança ou adolescente vítima ou testemunha de violência perante autoridade policial ou judiciária".

O legislador optou pela não utilização do termo "sem dano", antes popularizado. De fato, rememorar a violência, independentemente da linguagem utilizada, não garante inexistência de danos, não garante o impedimento da revitimização.

É preciso analisar a aplicação do depoimento especial e a constitucionalidade da lei a luz de princípios como a dignidade da pessoa humana e a proporcionalidade, que fazem parte da proteção integral. A proteção que se fala é a proteção de direitos da criança. Sem proteção de direitos fundamentais do ser humano, não há proteção da criança, não há proteção integral. O que se explica é que, com base na proteção integral da criança, já foi demonstrado que as interpretações são divergentes a respeito do depoimento especial, mas a proteção integral também deve ser interpretada à luz de outros princípios constitucionais. Da mesma forma, as garantias processuais de crianças e de adultos.

Ao escrever sobre as dimensões dos direitos fundamentais, Guerra Filho (2005, p. 30) menciona a dimensão processual com destaque às garantias constitucionais que devem ser interpretadas conforme os valores da própria constituição, e é com base nesse entendimento que se percebe a criança e o adolescente como seres em desenvolvimento, mas que são sujeito do direito à dignidade.

\title{
2 Depoimento especial sob a luz da dignidade da pessoa humana e proporcionalidade
}

A dignidade da pessoa humana impõe o respeito e a consideração entre as pessoas. $\mathrm{O}$ respeito, que envolve a liberdade em ser o que é, mas a consideração, que vai além e fortalece o compromisso de todos em não obstruir que o outro seja o que é, afastando ainda omissões, indiferença. Para Sarlet, dignidade da pessoa humana é: 
[...] a qualidade intrínseca e distintiva de cada ser humano que o faz merecedor do mesmo respeito e consideração por parte do Estado e da comunidade, implicando, neste sentido, um complexo de direitos e deveres fundamentais que assegurem a pessoa tanto contra todo e qualquer ato de cunho degradante e desumano, como venham a lhe garantir as condições existenciais mínimas para uma vida saudável, além de propiciar e promover sua participação ativa e corresponsável nos destinos da própria existência e da vida em comunhão com os demais seres humanos (SARLET, 2001, p. 60)

Pode-se, ainda, analisar a dignidade em duas dimensões. A dignidade como autonomia é o valor do indivíduo. Diz respeito à sua liberdade e seus direitos fundamentais. A partir dela se fala em pluralismo, diversidade, democracia. Já dignidade como heteronomia não depende apenas da liberdade individual. É, na verdade, um limite à liberdade de concepções de vida compartilhados. E nesse ponto é que entra a "busca pelo bem do outro", para a preservação da sociedade ou comunidade e aprimoramento moral do ser humano, entre outros objetivos (BARROSO, 2010, p. 21 e 26).

Para Barroso, “à luz do sistema jurídico brasileiro, é possível afirmar uma certa predominância da dignidade como autonomia, sem que se deslegitime o conceito de dignidade como heteronomia. $\mathrm{O}$ que significa dizer que, como regra geral, devem prevalecer as escolhas individuais" (2010, p. 32). Na infância, não prevalece a dignidade como autonomia, as escolhas individuais dos sujeitos de direito são substituídas pela escolha da família, ou do Estado, quando da destituição do poder familiar. No entanto, ainda diante da proteção da criança e do adolescente, é preciso observar o direito à dignidade como de escolha individual sempre que possível. Não por acaso, a Convenção sobre os Direitos da Criança prevê o direito à opinião no artigo 2 .

A escolha individual em falar ou não, em ouvir ou não as perguntas em um processo judicial que lhe diz interesse, considerando que as perguntas são reformuladas e adaptadas a uma linguagem acessível e respeitando a sua condição de desenvolvimento, pode ser uma forma de, por meio da lei 13.341, tornar eficaz a dignidade da pessoa humana heteronomia à criança.

Costuma-se utilizar o termo eficácia para a realização do direito de forma estritamente jurídica, quando a norma garante toda a regulação necessária para a realização de determinado direito. Enquanto que efetividade depende de outras variáveis além do texto constitucional, envolvendo questões econômicas, políticas, culturais (DA SILVA, 2014, p. 22). Portanto a Lei 13.341, nesta visão, atribui eficácia ao princípio da dignidade da pessoa humana sob a análise da dimensão heteronomia.

Com o envolvimento das crianças e adolescentes enquanto sujeito de direito, que primordialmente serão respeitadas quanto a aceitar ou não falar no depoimento especial, o 
primeiro despertar é pela consciência do "direito a ter direitos", expressão eternizada por Hannah Arendt (1989, p. 332), direito a pertencer à humanidade e experimentar a própria humanidade garantindo seus próprios direitos. Direito de escolha, e direito de falar de suas necessidades.

A origem etimológica da palavra "infância”" consiste no silêncio (PAGNI, 2010, p. 100), e o novo paradigma da doutrina da proteção integral, que substitui a doutrina da situação irregular, envolve o direito da criança de falar e ser ouvida. O filósofo Kuhn (1998) desenvolveu o conceito de paradigma com significados diferentes. Para Kuhn, esses paradigmas podem ser fortalecidos, transformados, abandonados, trocados, conforme a evolução científica do assunto. A troca de paradigma não anula ou torna incorreto o paradigma anterior, mas representa uma revolução no momento da troca, pois no tempo atual já não cabe manter aquele paradigma.

No entanto, considerando que o depoimento especial, conforme os seus críticos, interfere na proteção integral provocando a revitimização da criança e, ainda, interfere na ampla defesa do acusado de abuso sexual, abrindo portas a falsas memórias, é necessária a abordagem do assunto sob a luz da proporcionalidade.

Quando se fala em proporcionalidade é preciso analisar a medida estatal, neste caso a Lei 13.341, em três fases. Embora seja chamada de princípio, a proporcionalidade tem estrutura de regra, conforme Virgílio Afonso da Silva (2017). Toda medida do Estado deve passar pelo filtro da proporcionalidade.

Em primeira fase, a proporcionalidade leva a análise da adequação. A pergunta feita é: Esta medida traz alguma solução para o objetivo almejado? Para alguns autores essa solução precisa ser integral, para outros ela pode resolver de forma parcial a questão. No entendimento de Virgílio Afonso da Silva, é inviável exigir que uma medida solucione comprovadamente de forma integral um problema (DA SILVA, 2017, P. 170).

Nesse sentido, a Lei 13.341 promove o direito da criança em ser ouvida de uma forma menos desgastante emocionalmente, a fim de resguardar a dignidade e simultaneamente a sua proteção integral. Isso, pois, se utiliza da sala especial, do profissional qualificado com a linguagem menos violenta, a não exposição frente a frente com mais desconhecidos (juiz, promotor, defensor). Falar sobre a experiência de ser vítima de violência dificilmente, como já dito, será imune a danos, no entanto, em comparação com o tradicional depoimento, de fato há um esforço em preservar a saúde mental da criança.

Ainda no filtro da adequação, com vistas a garantir o artigo 201 do Código de Processo Penal, que é ouvir a vítima, e ao mesmo tempo garantir o respeito à condição peculiar de desenvolvimento da criança, pode-se considerar que o depoimento especial é adequado, embora 
não seja integralmente perfeito, como nenhuma escuta de violência poderia atingir tal patamar. Pois o ideal será sempre que a violência nunca tenha existido.

Um segundo filtro quando se fala em proporcionalidade é o de necessidade. Nesse caso, além de analisar se a medida estatal é adequada, é preciso ainda que haja outras medidas para comparar, se existem formas de atingir o mesmo objetivo com um meio menos agressivo a outros direitos ou mais eficientes (DA SILVA, 2017, p. 173).

No caso, pode-se considerar na comparação um depoimento tradicional, de uma vítima adulta. As perguntas podem ser mais diretas, as respostas para uma instrução probatória mais eficientes, mas a violação da proteção integral e da consideração da criança em estágio de desenvolvimento seria inevitável, anulando o núcleo essencial desses direitos. Já, se o depoimento especial for comparado com uma escuta em que não haja participação alguma do juiz e do promotor, garantindo integralmente o afastamento da revitimização com a justificativa de proteção integral, o direito da criança à escolha individual a ser ouvida no processo judicial que apura fatos que lhe dizem respeito, será completamente anulado. Por outro lado, se ela não for ouvida de forma alguma, a omissão do Estado estará instalada por completo em relação a esse sujeito de direito que é a criança.

Quanto a análise da necessidade, nem sempre a medida mais eficiente será a proporcional, pois assim o Estado poderia cometer diversas arbitrariedades alegando a total eficiência de medidas que restringem completamente outros direitos. Ainda, nem sempre a medida menos gravosa a outros direitos será a medida proporcional, pois assim não haveria análise de medida alguma, pois sempre a omissão do Estado será menos restritiva do que qualquer medida a ser tomada.

O depoimento especial necessário é aquele que respeita os direitos da criança, afasta as características traumáticas de um depoimento especial, atendendo à acepção estrita e ampla do direito da criança de ser ouvida. Sobre o assunto, Alkimin destaca, inclusive, que não seja marcada data e hora para ouvir crianças: 
O direito à oitiva da criança vitimada pelo abuso sexual integra o sistema especial de justiça, sendo o direito de ser ouvida uma garantia fundamental, contudo, deve ser ouvida separadamente do agressor em ambiente que favoreça a sua espontaneidade e segurança emocional, inclusive, respeitando-se a vontade manifestada pela criança de ser ouvida no tempo que lhe aprouver, ou seja, não se pode fixar e impor dia e horário, deve noticiar à criança e deixa-la livre e à vontade, ou seja, é um direito fundamental que deve ser exercido e não exigido, logo, a oitiva deve atentar ao estado de vulnerabilidade e sensibilidade da criança. O direito de ser ouvido envolve uma acepção estrita e outra ampla. No sentido estrito, entende-se como o direito que tem o menor de ser escutado por quem deve adotar uma resolução sobre questões que o afetam ou que afetarão. No sentido amplo, acaba abrangendo o estrito, contudo, se amplia para ouvir a opinião, desejo ou manifestação que deverá ser levada em conta pelo julgador, em maior ou menor medida, desde que se acolha em razão do melhor interesse da criança e do adolescente. (ALKIMIN, 2016, p. 16)

Por fim, na análise da proporcionalidade, há o filtro da proporcionalidade em sentido estrito, que contabiliza o equilíbrio entre o objetivo da medida e os males causados por essa medida, as violações de direito que ela provoca. Nesse caso, a discussão sobre o depoimento especial deve considerar as críticas em divergência às justificativas da aplicação da lei. A respeito do tema, Virgílio Afonso da Silva conclui que "mais importante que buscar fórmulas matemáticas é a busca de regras de argumentação, critérios de valoração ou a fundamentação de precedências condicionadas" (2017, p. 176).

É importante, portanto, que o depoimento especial seja aplicado de forma a respeitar na prática a vontade da criança, em falar ou não falar, sem induzimento das respostas, e sem repetição do relato em diversos órgãos e instituições de proteção.

\section{Depoimento especial no estado de Mato Grosso do Sul}

Em abril de 2014, o Tribunal de Justiça de Mato Grosso do Sul criou a Central de Depoimento Especial. De acordo com dados da Coordenadoria da Infância e Juventude do Tribunal, até o dia 9 de março de 2020, foram ouvidas 1.337 pessoas por meio da técnica do depoimento especial. Entre crianças e adolescentes, dessas, 1.151 foram ouvidas na condição de vítimas de violência sexual, sendo o restante testemunhas - a respeito de um dos processos a informação não consta. 
Figura 1 - Tabela e gráfico com a quantidade de adolescentes e crianças ouvidas como testemunhas e vítimas por meio do depoimento especial em Mato Grosso do Sul de abril de 2014 a 9 de março de 2020

\begin{tabular}{|lll|}
\hline COMARCA & TIPO & QUANTIDADE \\
\hline Campo Grande & testemunha & 174 \\
\hline Campo Grande & vítima & 1118 \\
\hline Aquidauana & vítima & 4 \\
\hline Bandeirantes & vítima & 1 \\
\hline Camapuã & testemunha & 1 \\
\hline Camapuã & vítima & 4 \\
\hline Coxim & vítima & 8 \\
\hline Corumbá & vítima & 1 \\
\hline Dourados & não consta & 8 \\
\hline Miranda & testemunha & 2 \\
\hline Miranda & vítima & 1 \\
\hline Nova Alvorada do Sul & vítima & 7 \\
\hline Iguatemi & vítima & 1 \\
\hline Pedro Gomes & testemunha & 1 \\
\hline Rio Negro & vítima & 2 \\
\hline São Gabriel do Oeste & vítima & 1 \\
\hline Terenos & vítima & 3 \\
\hline \hline TOTAL GERAL & & $\mathbf{1 3 3 7}$ \\
\hline
\end{tabular}

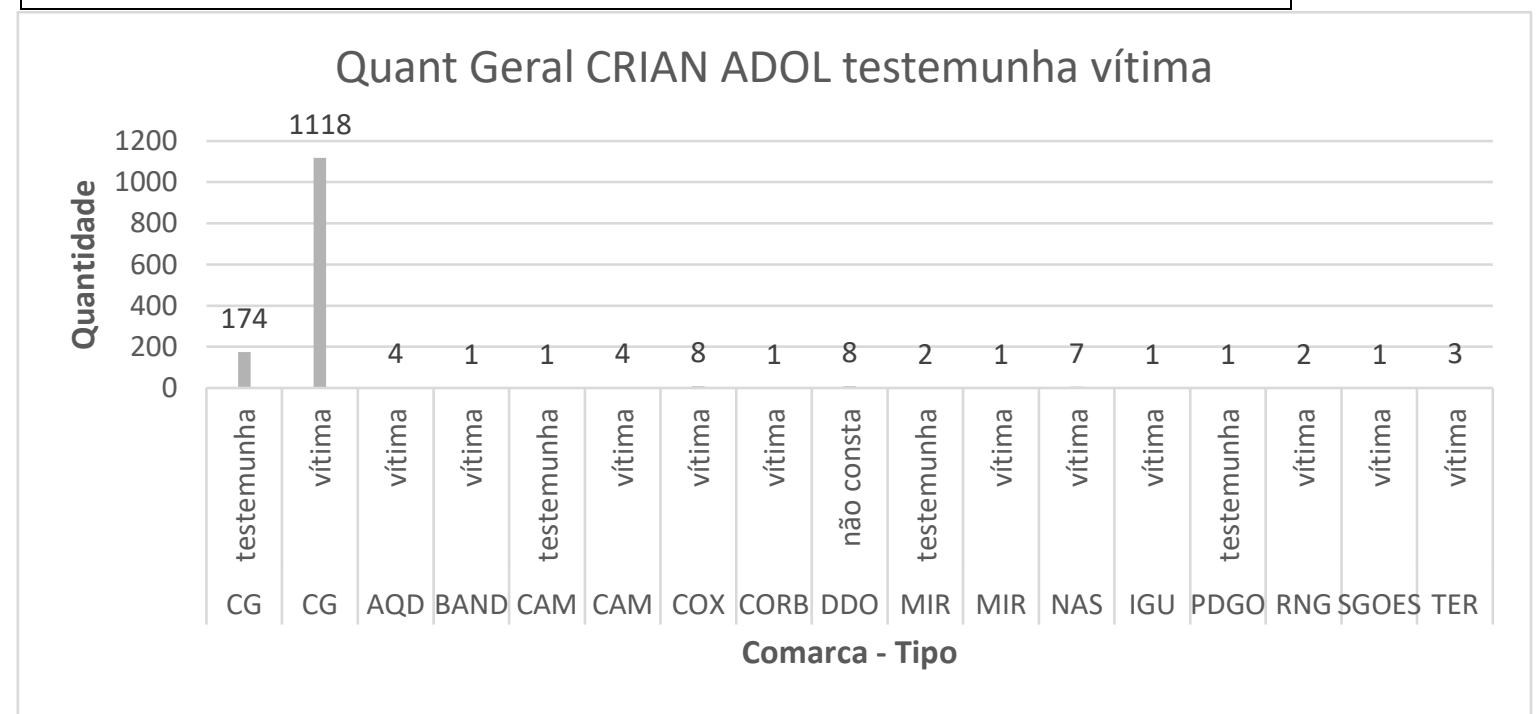

Fonte: Poder Judiciário de Mato Grosso do Sul - Comarca de Campo Grande - Departamento de Administração - Coordenadoria da Central de Depoimento Especial.

Insta destacar que dentre os 1.181 casos analisados quanto à relação da criança ou adolescente vítima com o acusado, em 782 casos a relação era de caráter intrafamiliar. O que corresponde a cerca de $66 \%$ dos processos. Conforme o gráfico que apresenta o sexo das pessoas ouvidas no depoimento especial, mais de $74 \%$ são do sexo feminino. Dos 1.335 casos que apresentam a informação, 997 são meninas e 338 meninos. 
Figura 2 - Tabela e gráfico com a quantidade de tipos de violência (intrafamiliar ou extrafamiliar) das quais foram vítimas as crianças e adolescentes ouvidas como testemunhas e vítimas por meio do depoimento especial em Mato Grosso do Sul de abril de 2014 a 9 de março de 2020

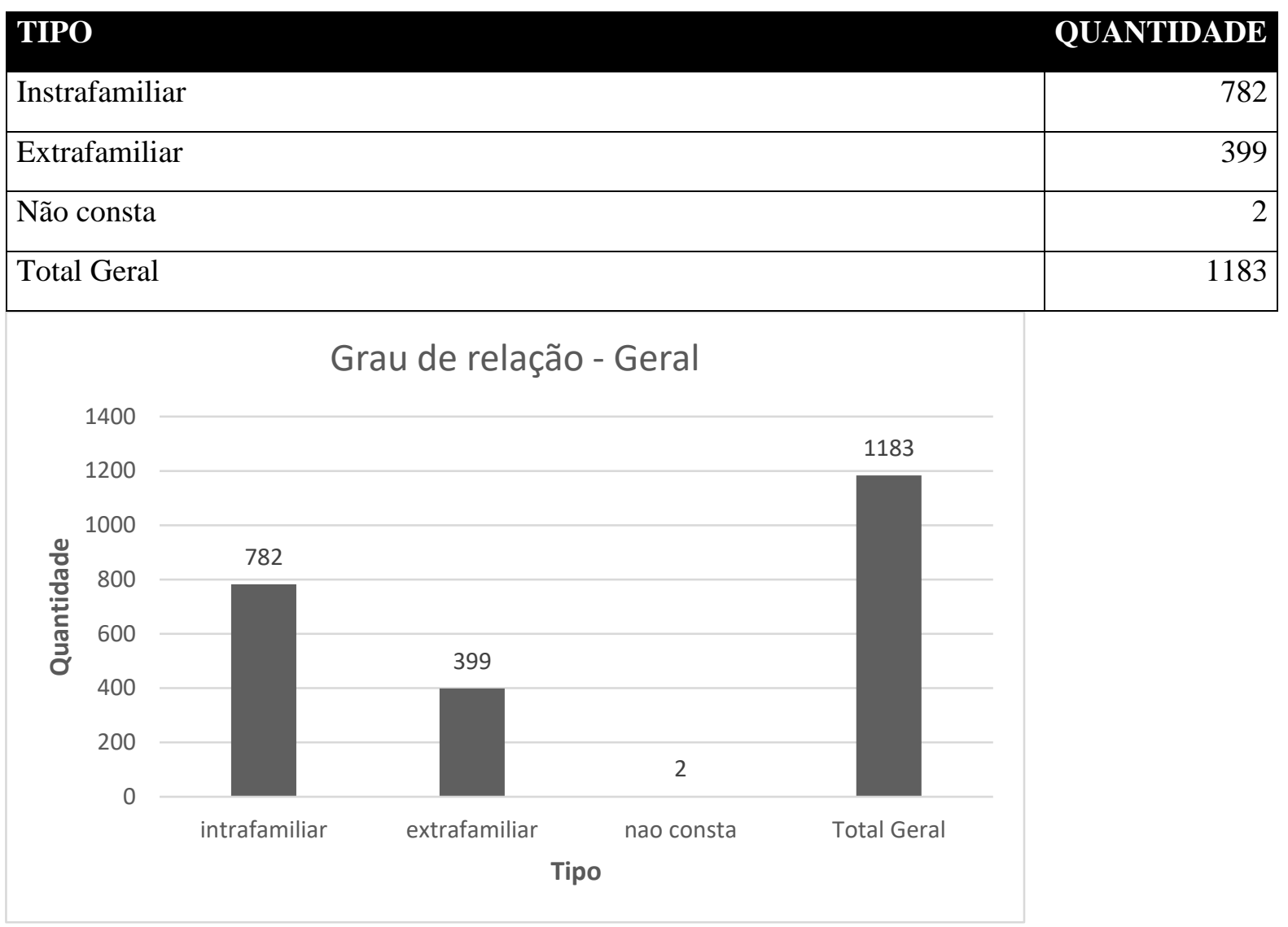

Fonte: Poder Judiciário de Mato Grosso do Sul - Comarca de Campo Grande - Departamento de Administração - Coordenadoria da Central de Depoimento Especial. 
Figura 3 - Tabela e gráfico com a quantidade de adolescentes e crianças, por idade e sexo, ouvidos pela técnica do depoimento especial entre de abril de 2014 a 9 de março de 2020 em Mato Grosso do Sul

\begin{tabular}{|llr|}
\hline Idade agrupada & Sexo & \multicolumn{1}{c|}{ Quantidade } \\
\hline $02-12$ & Feminino & 726 \\
\hline $13-24$ & Feminino & 271 \\
\hline $02-12$ & Masculino & 256 \\
\hline $13-18$ & Masculino & 82 \\
\hline 05 & Não consta & 1 \\
\hline \hline TOTAL & & $\mathbf{1 3 3 6}$ \\
\hline
\end{tabular}

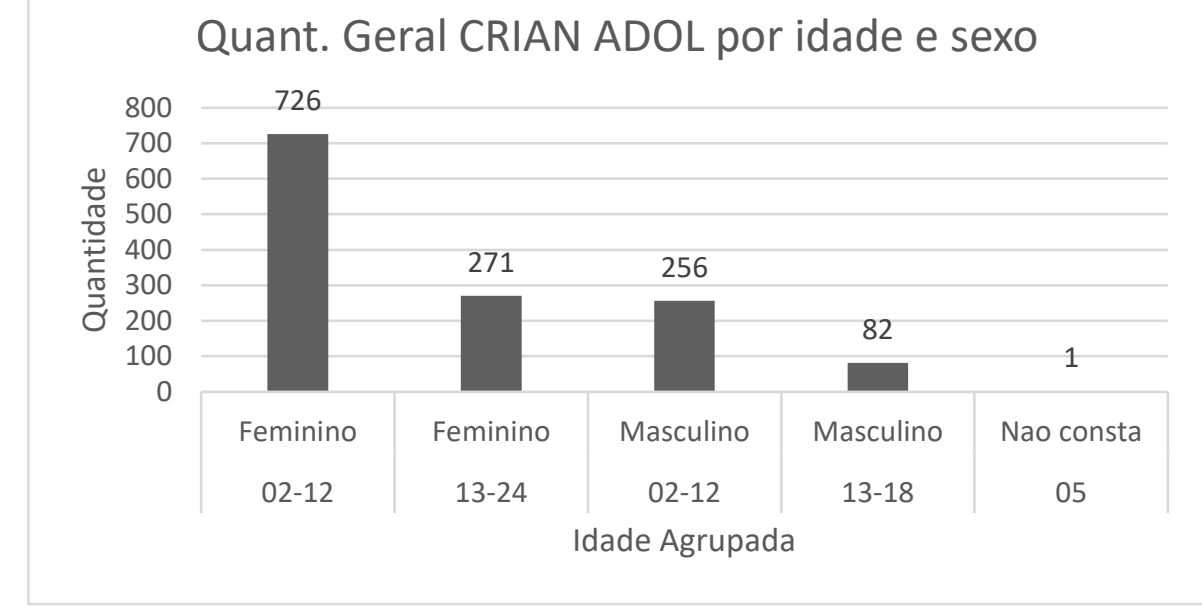

Fonte: Poder Judiciário de Mato Grosso do Sul - Comarca de Campo Grande - Departamento de Administração - Coordenadoria da Central de Depoimento Especial.

Quanto aos acusados, a informação é de que dentre 1.182 processos, 82 mulheres são acusadas, e 1100 homens são acusados. As idades dos acusados chamam atenção para a adolescência, afinal, 236 desses acusados do sexo masculino possuem entre 12 e 20 anos, sendo que 200 deles têm entre 21 e 30 anos de idade. Isso demonstra o quanto a conscientização da criança sobre sexualidade pode influenciar tanto na conduta dela como vítima, mas também para não ser o agressor de outra criança, principalmente em relação aos meninos. 
Figura 4 - Tabela e gráfico com a quantidade e idade de acusados do sexo masculino dos processos com depoimento especial entre de abril de 2014 a 9 de março de 2020 em Mato Grosso do Sul

\begin{tabular}{|lr|}
\hline SEXO MASCULINO & \\
ANOS IDADE & QUANT. ACUSADOS \\
\hline 12 - 20 anos & 236 \\
\hline $21-30$ anos & 200 \\
\hline $31-40$ anos & 158 \\
\hline $41-50$ anos & 128 \\
\hline $51-60$ anos & 64 \\
\hline $61-70$ anos & 43 \\
\hline $71-84$ anos & 5 \\
\hline Não consta & $\mathbf{1 1 0 0}$ \\
\hline \hline Soma & \\
\hline
\end{tabular}

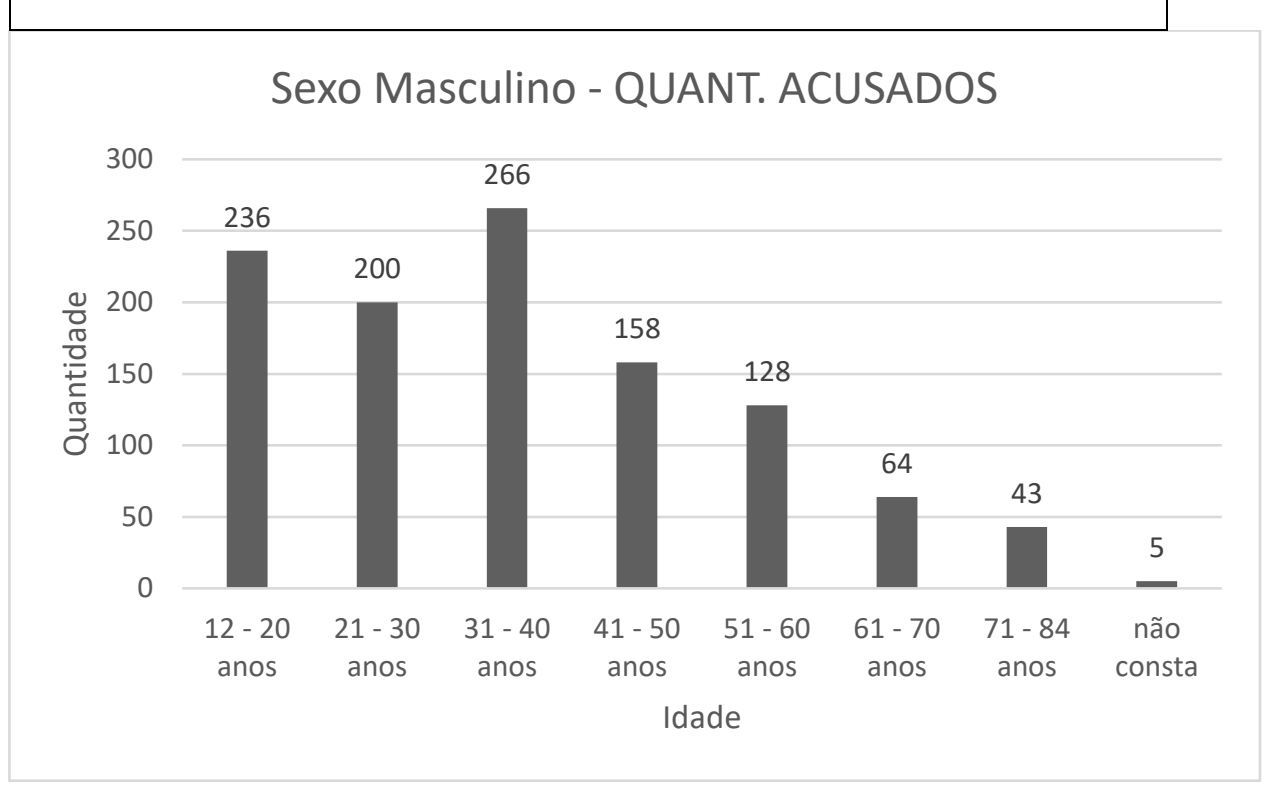

Fonte: Poder Judiciário de Mato Grosso do Sul - Comarca de Campo Grande - Departamento de Administração - Coordenadoria da Central de Depoimento Especial. 
Figura 5 - Tabela e gráfico com a quantidade e idade de acusadas do sexo feminino dos processos com depoimento especial entre de abril de 2014 a 9 de março de 2020 em Mato Grosso do Sul

\begin{tabular}{|c|c|}
\hline \multicolumn{2}{|c|}{ SEXO FEMININO } \\
\hline $\begin{array}{l}\text { ANOS } \\
\text { IDADE }\end{array}$ & QUANT. ACUSADOS \\
\hline $13-27$ anos & 23 \\
\hline $29-41$ anos & 42 \\
\hline $42-67$ anos & 13 \\
\hline não consta & 4 \\
\hline TOTAL & 82 \\
\hline
\end{tabular}

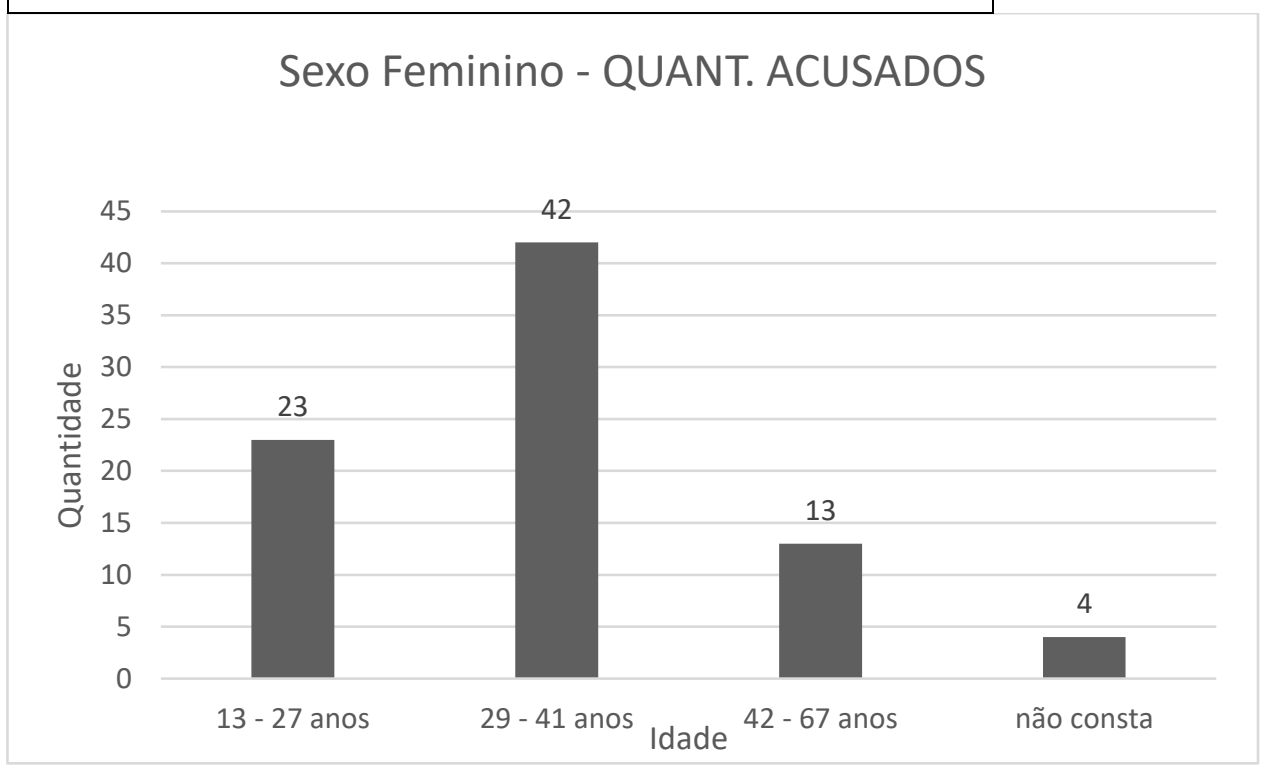

Fonte: Poder Judiciário de Mato Grosso do Sul - Comarca de Campo Grande - Departamento de Administração - Coordenadoria da Central de Depoimento Especial.

Quanto as críticas sobre a indução de crianças para a instrução probatória forçada na busca da verdade real, um dado interessante do depoimento especial em Mato Grosso do Sul é que dentre 792 sentenças condenatórias ou absolutórias, de abril de 2014 a março de 2020, há um relativo equilíbrio, visto que 379 são absolutórias e 413 são condenatórias. Caso o depoimento especial fosse uma forma de criação de uma prova que afetasse a ampla defesa, haveria essa diferença de menos de 5\%? É algo que com o pouco tempo de aplicação do depoimento especial, seis anos, e apenas três regulado por lei, ainda não é possível responder.

Em cenário nacional, relatório publicado pelo Conselho Nacional de Justiça em 2019 apresenta estudo da aplicação da Lei 13.431 de 2017 nos estados do Pará, Ceará, Distrito 
Federal, Goiás, São Paulo e Rio Grande do Sul. A pesquisa foi realizada mediante quatro eixos: o primeiro relativo ao local onde é realizado o depoimento especial, mais ligado à estrutura; o segundo eixo relativo à localização em relação à sala de audiências e do risco de contato entre vítima e agressor; um terceiro eixo sobre os móveis, materiais utilizados, estantes, brinquedos, que compõem o ambiente no qual a criança será recebida; e o quarto eixo sobre equipamento e apoio técnico para a realização da videoconferência no procedimento (Conselho Nacional de Justiça, 2019).

Figura 6 - Tabela e gráfico com a quantidade e tipo de sentenças proferidas em processos com depoimento especial entre de abril de 2014 a 9 de março de 2020 em Mato Grosso do Sul

\begin{tabular}{|llr|}
\hline COMARCA & TIPO & QUANTIDADE \\
\hline Campo Grande & absolutória & 377 \\
\hline Campo Grande & condenatória & 408 \\
\hline Campo Grande & sentença civil & 21 \\
\hline Coxim & condenatória & 1 \\
\hline Dourados & absolutória & 1 \\
\hline Dourados & condenatória & 1 \\
\hline Miranda & condenatória & 1 \\
\hline $\begin{array}{l}\text { Nova Alvorada do } \\
\text { Sul }\end{array}$ & condenatória & 1 \\
\hline $\begin{array}{l}\text { Nova Alvorada do } \\
\text { Sul }\end{array}$ & sentença civil & 1 \\
\hline Pedro Gomes & condenatória & 1 \\
\hline \hline TOTAL GERAL & & $\mathbf{8 1 3}$ \\
\hline
\end{tabular}

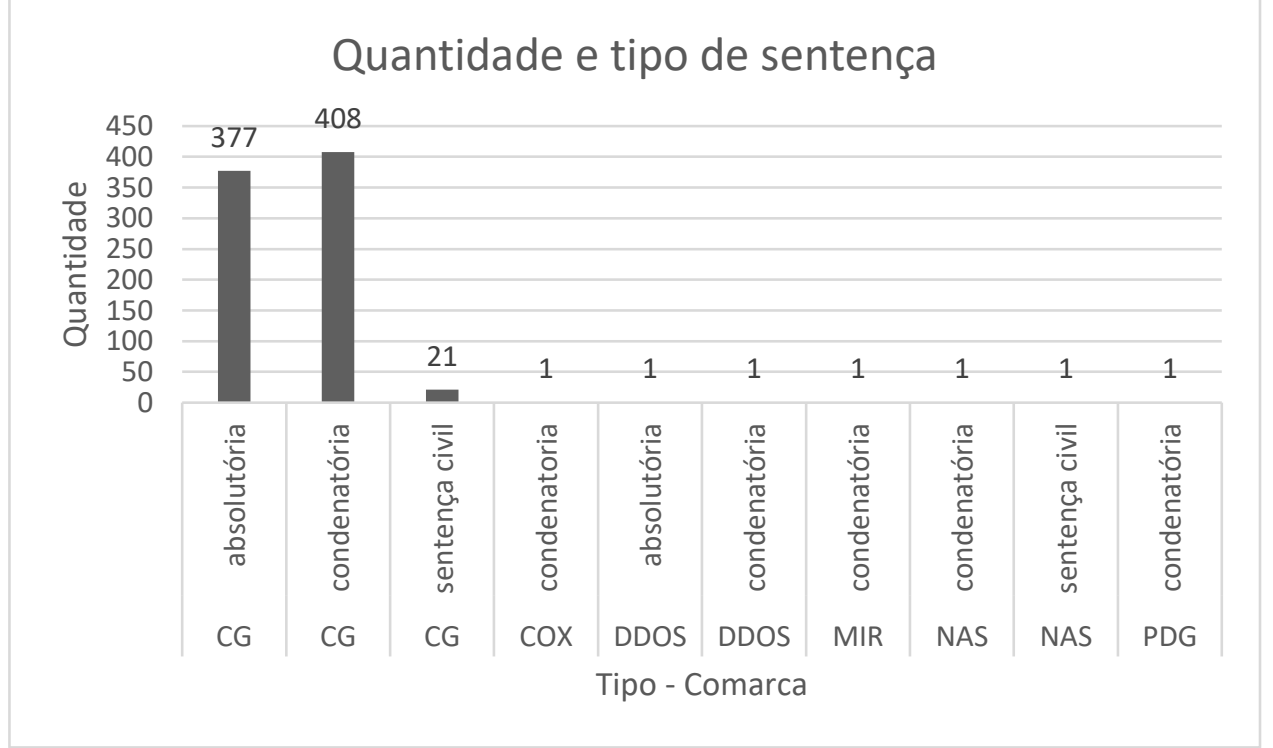

Fonte: Poder Judiciário de Mato Grosso do Sul - Comarca de Campo Grande - Departamento de Administração - Coordenadoria da Central de Depoimento Especial. 
É possível perceber no estudo que a maior dificuldade atual do depoimento especial no Brasil não diz respeito à eficácia, visto que antes era algo realizado por regulamento administrativo e, hoje, tem uma lei que o instituiu formalmente no sistema normativo. As dificuldades são de efetividade, por implicar em questões sociais, econômicas, dos tribunais brasileiros, conforme a problemática apontada:

\footnotetext{
Diante dos pontos necessários à devida implementação do Depoimento Especial pelo Poder Judiciário brasileiro, ao longo do processo da pesquisa, foi verificada a possibilidade de apresentação dos seguintes problemas. O elenco de situações é exemplificativo, porém, deve-se considerar que precisam ser constatados e sanados pelos responsáveis da administração judiciária: (1) Falta de pessoal; (2) Ausência de capacitação; (3) Deficiência estrutural; (4) Gestão precarizada por falta de atenção; (5) Ausência de escolha e uniformidade de Protocolo; (6) Questão relativa à destinação orçamentária para estruturação da política judiciária de implementação do Depoimento Especial. (Conselho Nacional de Justiça, 2019, p. 142)
}

A fase é de aperfeiçoamento em todo o país. Em Mato Grosso do Sul, a estrutura das salas, a capacitação de servidores é uma preocupação que teve início antes da promulgação da Lei 13.341 de 2017. No ano de 2016, uma juíza publicou estudo relacionado à prática pelo Tribunal de Justiça de Mato Grosso do Sul, com dados de processos de 2014 até aquele ano, já demonstrando no estudo os ambientes nos quais as crianças eram ouvidas. Com a prática há aperfeiçoamento, tanto nas questões que envolvem a economia e gestão das instituições quanto questões que envolvem a abordagem voltada para a garantia das crianças de proteção integral, prioridade absoluta e dignidade.

Ocorreu um movimento mundial entre as décadas de 80 e 90 para que crianças e adolescentes deixassem de serem tratados como elemento de regulação do Estado, na antiga doutrina da situação irregular, para serem sujeitos de direito, na doutrina da proteção integral, o que foi positivado em diversos documentos internacionais, além da Constituição Federal e do Estatuto da Criança e do Adolescente.

Ao reconhecer a criança enquanto sujeito de direito, é inerente o reconhecimento da garantia da dignidade da pessoa humana a esses indivíduos em formação. Além da prevenção da violência, isso envolve o tratamento de crianças e adolescentes que foram violentados e a punição de seus agressores. O Estado Democrático de Direito deve utilizar de todas as ferramentas possíveis para prevenir a violência e evitar a impunidade, esse é o entendimento na jurisprudência internacional como será exemplificado a seguir.

A respeito do direito da criança e do adolescente abordado internacionalmente, menciona-se o caso Paola Guzmán Albarracín vs Equador. Paola, conforme a Comissão Interamericana de Direitos Humanos, foi abusada sexualmente por dois funcionários públicos, 
um tinha cargo de liderança em sua escola, e o outro era médico da instituição de ensino que ela frequentava. A menina foi abusada sexualmente e, por conta dos abusos, engravidou, foi obrigada a cometer um aborto, e acabou por praticar suicídio aos 16 anos de idade, deixando uma carta à mãe e duas cartas ao seu agressor, nas quais detalhava como ocorriam os abusos.

Ela sofreu violência sexual pelos funcionários públicos e a Comissão Interamericana de Direitos Humanos entendeu que há um nexo de causalidade entre os abusos e a sua decisão de se matar. No relatório, a Comissão sustentou que o Estado do Equador violou o dever de respeitar os direitos humanos, a obrigação de garantir a prevenção e detecção precoce para a situação, não utilizando ferramentas necessárias. Ainda, foi concluído que a impunidade no caso se deve à falta de diligência pelas autoridades (CIDH, 2019).

Em janeiro de 2020 ocorreu audiência pública sobre o caso na Corte Interamericana de Direitos Humanos, onde um dos pontos discutidos foi a questão do silêncio da adolescente, o medo, a solidão diante da vulnerabilidade em viver em um Estado onde não há prevenção ou punição a este tipo de violência (CIDH, 2020). O Brasil, por sua vez, já assinou acordo com a Comissão Interamericana de Direitos Humanos, ao reconhecer responsabilidade no Caso Meninos Emasculados do Maranhão, se comprometendo a promover políticas públicas de nãorepetição de violações de direitos de crianças e adolescentes no país (BRASIL, 2005).

Portanto, é um compromisso da nação, do Estado brasileiro, um compromisso de toda sociedade, das autoridades, de todos os poderes, incluindo o Poder Judiciário. Um compromisso que envolve utilizar ferramentas para que o silêncio não perpetue a violência e o abuso sexual de meninas e meninos. Em relatório sobre o procedimento do depoimento especial no Brasil, o Conselho Nacional de Justiça reforçou esse entendimento:

\footnotetext{
A oitiva de crianças vítimas ou testemunhas de violência envolve legislação nacional e internacional que têm por norte a proteção integral da criança, a busca da efetividade do processo e a coerente punição do agressor. Assim, cabe ao Poder Judiciário assegurar os direitos infanto-juvenis, garantir a inviolabilidade da dignidade e o respeito à integridade física e psicológica nos processos em que seja necessária a escuta da criança ou do adolescente. Ambiciona-se, de forma ampla, o comprometimento máximo com o desenvolvimento harmônico e pleno da pessoa menor de dezoito anos na própria ação institucional do Poder Judiciário. (CONSELHO NACIONAL DE JUSTIÇA, 2019)
}

É preciso, então, utilizar todas as ferramentas necessárias para a garantia de direitos de crianças e adolescentes. $\mathrm{O}$ depoimento especial, embora necessite de aperfeiçoamento como o sistema normativo e jurídico em geral, se utilizado conforme os princípios gerais e específicos do direito da criança, pode ser uma das ferramentas para garantia da proteção e para evitar a impunidade. 


\section{Conclusão}

Antes conhecida como Depoimento Sem Dano, a técnica do Depoimento Especial, instituída por lei em 2017, garante que crianças e adolescentes em situação de violência sexual sejam ouvidos em uma sala separada da sala de audiência, por um técnico qualificado na escuta especial. Juiz, promotor e defensor ou advogado permanecem na sala de audiência acompanhando a escuta da criança por vídeo.

No formato atual, os juízes, promotores e defensores podem fazer questionamentos ao técnico de depoimento especial por meio de um ponto de escuta, e o técnico reformula as perguntas ao se comunicar com a criança, a fim de utilizar a linguagem adequada à situação e à idade. A entrevista é gravada e anexada aos autos do processo judicial.

O depoimento especial está em aperfeiçoamento, surgiu da experiência do poder judiciário do Rio Grande do Sul, na comarca de Porto Alegre em 2003, teve início sem respaldo legal, mas regulamentação interna, depois foi regulado em âmbito nacional administrativamente pela Recomendação 33 do Conselho Nacional de Justiça e, anos depois, instituído em lei.

Ter sido positivado no ordenamento jurídico não significa que não comporta questionamentos, que não precisa de novos olhares e de cuidado de todos os atores envolvidos em sua prática, e dos profissionais que se submetem à formação necessária para as entrevistas, para adequar discurso, norma escrita, e prática. No entanto, pode-se dizer que sendo uma garantia à criança, o direito de ser ouvida, o depoimento especial pode passar por adequações, mas ser extinguido ou voltar ao modelo tradicional anterior, no qual a criança não tinha sua individualidade e estágio de desenvolvimento respeitados, representaria retrocesso.

Isso, pois, considerando a pesquisa bibliográfica e os dados apresentados neste artigo, acredita-se que a resposta é positiva quanto ao depoimento especial ser manifestação do reconhecimento da criança enquanto sujeito de direito. A hipótese de que a técnica apresenta mais harmonia com os princípios de proteção integral e prioridade absoluta, em comparação com os métodos tradicionais de oitiva é confirmada diante dos dados apresentados.

O direito a falar e a se manter calado é explorado no caso concreto, respeitando a individualidade da criança, respeitando a condição de desenvolvimento, a urgência com que ela deve ser ouvida, a não repetição do depoimento. Ao menos, é assim que deve ser conforme a própria legislação e quem defende a sua constitucionalidade e a sua convencionalidade.

$\mathrm{Na}$ análise da proteção integral, sendo interpretada em conjunto com os demais princípios constitucionais, verifica-se que o depoimento especial pode ser classificado como 
uma ferramenta do Estado na garantia de direitos de crianças e adolescentes. Instrumento dotado de proporcionalidade em relação às suas fragilidades, sendo adequado e necessário, e um meio de concretizar o direito da criança a ser ouvida, na busca pela sua dignidade e condição de sujeito de direito.

Quanto aos dados do estado de Mato Grosso do Sul, foi possível verificar que desde 2014, três anos antes da edição da lei que instituiu o depoimento especial, mais de mil vítimas crianças ou adolescentes foram ouvidas por meio da técnica. Também foi visto que esse número tampouco significou condenação dos supostos agressores na totalidade dos casos e que o Tribunal de Justiça tem investido em pessoal e estrutura para a aplicação da Lei 13.431 de 2017, considerando os eixos e desafios do Poder Judiciário brasileiro apresentados em relatório do Conselho Nacional de Justiça em 2019.

Ver a criança enquanto sujeito de direito exige uma ruptura. É preciso sair do silêncio e enxergar o responsável pela violação de direitos, mesmo que ele seja alguém próximo, de confiança da família. A criança enquanto sujeito de direito não é propriedade dos pais, tampouco do Estado. É preciso ouvi-la, sem a justificativa de que se sabe o que é bom para ela sem ir muito além desse discurso.

\section{REFERÊNCIAS}

ALKIMIN, Maria Aparecida. A concretização do Superior Interesse da criança e do adolescente diante do direito e garantia fundamental de participação em processo de abuso sexual intrafamiliar. Artigo aprovado e publicado no XXV Encontro Nacional do CONPEDI. Brasília, 2016. Disponível em:

http://conpedi.danilolr.info/publicacoes/y0ii48h0/45bgwp70/7Nc5n90gXVwt7F2s.pdf. Acesso em:5 jul. 2020.

ARENDT, Hannah. Origens do Totalitarismo - Antissemitismo, Imperialismo, Totalitarismo. Trad. Roberto Raposo. São Paulo: Companhia das Letras, 1989.

BARROSO, Luís Roberto; MARTEL, Letícia de Campo Velho. A morte como ela é: Dignidade e autonomia individual no final da vida. Revista da EMERJ, v. 13, nº 50, 2010. Disponível em:

https://www.emerj.tjrj.jus.br/revistaemerj_online/edicoes/revista50/Revista50_19.pdf . Acesso em: 25 jun. 2020.

BRASIL. Constituição da República Federativa do Brasil. Brasília, Senado Federal, 1988.

BRASIL. Decreto-Lei 3.689, de 3 de outubro de 1941. Código de Processo Penal. Diário Oficial da União, Brasília, 13 de outubro de 1941. 
OLIVEIRA, Ana Maria Assis de; ARRUDA, Rejane Alves de. Criança enquanto sujeito de direito no depoimento especial e a experiência em Mato Grosso do Sul

BRASIL. Lei n. 8.069, de 13 de julho de 1990, Dispõe sobre o Estatuto da Criança e do Adolescente e dá outras providências. Diário Oficial da União, Brasília, 16 jul. 1990.

CEZAR, José Antônio Daltoé. Depoimento Sem Dano: uma alternativa para inquirir crianças e adolescentes nos processos judiciais. Porto Alegre: Livraria do Advogado, 2007.

CEZAR, José Antônio Daltoé. A escuta de crianças e adolescentes em juízo: uma questão legal ou um exercício de direitos. In: BITENCOURT, L. P. (org.). Depoimento Sem Dano: uma política criminal de redução de danos. Rio de Janeiro: Lumen Juris, 2010. p. 71-86.

CONSELHO FEDERAL DE PSICOLOGIA (CFP). Nota técnica sobre os impactos da Lei 13.431 de 2017 na atuação das psicólogas e psicólogos. 2018. Disponível em: http://site.cfp.org.br/wp-content/uploads/2018/01/NOTA-TECNICA-N\%C2\%BA1_2018_GTEC_CG.pdf. Acesso em: 27 maio 2020.

CONSELHO NACIONAL DE JUSTIÇA. A oitiva de crianças no poder judiciário brasileiro: Relatório Analítico Propositivo. Brasília, 2019.

CONSELHO NACIONAL DE JUSTIÇA. Recomendação 33 de 2010. Diário de Justiça Eletrônico n. 215/2010, de 25 de novembro de 2010, p. 33-34.

COSTA, T. N. G.; RIBAS, L. M. Inovação na jurisdição Estatal: de Contenciosa para uma Jurisdição Singular, compartilhada, Efetiva, Democrática e Emancipatória. Conpedi Law Review, v. 3, p. 190-215, 2017. Disponível em:

https://www.indexlaw.org/index.php/conpedireview/article/view/3682/0. Acesso em: 08 maio 2020.

DA SILVA, Virgílio Afonso. Direitos Fundamentais. Conteúdo Essencial, Restrições e Eficácia. 2 ed. São Paulo: Malheiros, 2017.

DE AZAMBUJA, Maria Regina Fay. Inquirição da criança vítima de violência sexual: proteção ou violação de direitos? 2. ed. Livraria do Advogado. Porto Alegre, 2017.

DE SOUZA, Jadir Criqueira. Depoimento especial de crianças e adolescentes no sistema de justiça. Editora Pilares. São Paulo, 2018.

GLOECKNER, Ricardo Jacobsen. Depoimento sem dano? Das funções não declaradas ao regime de heteroveridição no processo penal. Revista Liberdades, agosto 2016. Disponível em: https://www.ibccrim.org.br/publicacoes/redirecionaLeituraPDF/7467. Acesso em: 5 julho 2020 .

GUERRA FILHO, W.S. Processo constitucional e direitos fundamentais. 7. ed. São Paulo: SRS Editora, 2017.

KUHN, Thomas Samuel. A estrutura das revoluções científicas. São Paulo: Perspectiva, 1998.

LOPES JÚNIOR, Aury; DA ROSA, Alexandre Morais. Depoimento Especial é antiético e pode levar a erros judiciais. Conjur, 2015. Disponível em: https://www.conjur.com.br/2015- 
jan-23/limite-penal-depoimento-especial-antietico-levar-erros-judiciais. Acesso em: 26 maio 2020.

ORGANIZAÇÃO DAS NAÇÕES UNIDAS. Convenção sobre os direitos da criança. Assembleia Geral da ONU, 1989.

PAGNI, Pedro Ângelo. Infância, arte de governo pedagógica e cuidado de si. Educação e Realidade, Porto Alegre, v. 35, n. 3, p. 99-123, set./dez., 2010. Disponível em: https://www.redalyc.org/pdf/3172/317227078007.pdf. Acesso em: 25 maio 2020.

PÖTTER, Luciana (org.). A escuta protegida de crianças e adolescentes: os desafios da implantação da lei 13.431/2017. Livraria do Advogado. Porto Alegre, 2019.

PÖTTER, Luciana; HOFFMEISTER, Marceli V. (org.). Depoimento Especial de crianças e adolescentes: quando a multidisciplinariedade aproxima olhares. Livraria do Advogado. Porto Alegre, 2016.

RIBEIRO, Daniela Gonçalves Menengoti; DE ÁVILA, Gustavo Noronha; ZAVATTARO, Mayra dos Santos. O sistema interamericano e o direito da criança em prestar declarações no processo penal: garantias para reconhecimento de sua personalidade. Revista Jurídica Cesmumar, 2017, v. 17, n. 3, p. 891-915. Disponível em: https://periodicos.unicesumar.edu.br/index.php/revjuridica/article/view/6177. Acesso em: 2 jul. 2020.

ROCHA, Maria Isabel de Matos. Depoimento especial de crianças e adolescentes vítimas de violência sexual: a experiência do estado de Mato Grosso do Sul. Edição 20 da Revista IBDFAM - Famílias e Sucessões,. 2017. Disponível em: https://www.enfam.jus.br/wpcontent/uploads/2017/04/ARTIGO-Depoimento-Especial-MARIA-ISABELROCHA.R5K.pdf. Acesso em: 2 jul. 2020.

SARLET, Ingo Wolfgand. Dignidade da Pessoa Humana e Direitos Fundamentais na Constituição Federal de 1988. Porto Alegre: Livraria do Advogado, 2001.

SARMENTO, Daniel. Dignidade da pessoa humana: conteúdo, trajetórias e metodologia. 2. ed. Fórum. Belo Horizonte, 2016.

TRÉPANIER, J. Juvenile courts after 100 years: past and present orientations. European Journal on Criminal Policy and Research, 7, p. 303-327, 1999.

ZAVATTARO, Mayra dos Santos; AVILA, Gustavo Noronha. O depoimento infantil em juízo criminal: uma análise da Recomendação 33 do CNJ e a positivação através da Lei $n$. 13.431/2017. Artigo aprovado e publicado no XXVI Encontro Nacional do CONPEDI. Brasília, 2017. Disponível em: http://conpedi.danilolr.info/publicacoes/roj0xn13/9t8274u3/RVw9n4ISQK0Z6LgB.pdf Acesso em: 5 jul. 2020. 